\title{
A Mobile Based Application for Journey Safety
}

\author{
Nadia Akter ${ }^{1}$, Anisa Bente Newaz ${ }^{2}$, Amathul Hadi Shakara ${ }^{3}$, \\ Md. Abdullah Al Mamun ${ }^{4}$ \\ ${ }^{1,2,4}$ Department of Computer Science and Engineering, University of Development Alternative, Bangladesh \\ ${ }^{3}$ Department of Electrical and Telecommunication Engineering, University of Development Alternative, \\ Bangladesh
}

\begin{abstract}
Journey is an inseparable part of human life which is responsible for human civilization development.Worldwide a large portion of population daily travel for work, shopping, social reasons and many other purposes. Nowadays road accidents, hijacking, robbery, snatching, trap of fraud parties have increased in such a level that people are always concerned about the security and safety of life as well as property during journey. In maximum cases vehicle drivers are found involved with these incidents and victims can't complain to the related authority due to the lack of evidence.Also law enforcement agencies is unable to take proper action against these crimes due to the scarcity of adequate information. Women empowerment and their development is also lagging behind because of insecurity. In past few decades uses of mobile phones has increased enormously. Due to the rapid growth of mobile technology, smartphones are equipped with features likesensors, GPS navigation, digital camera, high speed internet connectivity and many more. Using these sophisticated features of smartphones, an application can be developed to overcome these problems of people and provide safety. Aim of this paper is to design a mobile application called 'Journey Safety' to overcome dangers mentioned above during journey and ensure complete safety.
\end{abstract}

Keywords: GPS tracking, Journey Safety, Security, Share, Smartphone.

\section{Introduction}

According to the Maslow's Hierarchy of needs, after fulfilling the physiological needs safety is the next basic need of human being. But people in low and middle income countries are deprived of this basic need and always concerned about safety of their life as well as property. Increasing Road Traffic Accidents (RTAs) are major threat to life in many parts of world. According to the 'World Report on Road Traffic Injury Prevention-2004', every year almost 1.2 million people are killed and people are being injured or disabled between 20 million and 50 million more in traffic accidents. Both WHO and World Bank data show that, without appropriate action, these injuries will rise dramatically by some $65 \%$ by the year 2020 , particularly in rapidly-motorizing countries and in low income and middle-income countries deaths are expected to increase by as much as $80 \%$ [1]. Road traffic accidents are a 'global tragedy' with ever-rising trends in fatalities and injuries in the developing countries. All known studies have also shown that, whilst road deaths are slowly decreasing in high income countries, low income countries face a worsening situation. According to WHO, speed is one of the risk factors influencing road accidents [2].

According to the latest WHO data published in May, 2014 Road Traffic Accidents Deaths in Bangladesh reached 16,842 or $2.31 \%$ of total deaths. The age adjusted Death Rate is 12.87 per 100,000 of population ranks Bangladesh is in 109 serial in the world. According to police report total number of road traffic accidents was 40,927 in Bangladesh during period of 2001-2010, and number of killed person was 32,261. In 2010, 3,300 people were killed in RTAs, which rose to 5,928 in 2011, a rise of $80 \%$. The estimated cost of road accident is 7,500 crore Bangladeshi taka (1 USD $=82 \mathrm{BDT}$ ) per year. This is said to be $1.5 \%$ of GDP [3].

According to a report on 'The Daily Star', in the year 2015 at least 8,642 people were killed and 21,855 others were injured in road crashes across the country. Of the injured, at least 1,305 became permanently disabled. Of the accidents, 56 percent took place on the highways, 23 percent in urban areas and 21 percent in rural areas. Overtaking, exceeding speed limits, overloading, disregarding traffic rules, engineering faults in road constructions, reckless driving, using headphones while driving and consuming drugs before driving were also held responsible for the accidents. Around 40 percent of the total accidents don't get media coverage at all [4].

People in countries like Bangladesh are always concerned about being a victim of mugging, robbery, snatching etc. at road. According to the statistics of 'Numbeo' which is the world's largest database of user contributed data about cities and countries worldwide, $71.39 \%$ people of Bangladesh are worried about being mugged or robbed. In Bangladesh people who are feeling safe to walk alone during daylight are only $48.26 \%$ and during night are only 25.86\% [5]. According to the report of the Secretary-General on the State of crime and criminal justice worldwide in 'Thirteenth United Nations Congress on Crime Prevention and Criminal Justice', robbery has increased in Asia and the percentage change for ten years (2003-2013) is 15\%+ [6]. For different reasons, 
such as lack of information, obstacles in physical accessibility, fear of stigmatization, lack of trust or corruption, crime victims may not report their experience to authorities and are thus already barred from access to justice at an early stage. The reporting rates for the crimes of robbery to police or other law enforcement agencies are lower in countries with higher prevalence rates for this crime, indicating that access to criminal justice tends to be lower exactly where there is more need for it [7]. To reduce crimes necessary information need to be delivered to the authority as early as possible.

\section{Research and study}

Mobile technology is improving rapidly. Uses of mobile phones are growing 58\% year over year [8]. Most of the mobile phones are used for personal uses. Modern smartphones are equipped with modern technology like GPS navigations system, various sensors, High resolution digital camera, High speed internet connectivity, Strong processing and capacity ability, long life battery benefit etc. Today Smartphones with android OS has occupied a large percentage in global market leaving other platforms behind [9]. These reports inspired the authors to develop an android application using modern technologies to solve the problems in $[1,7]$.

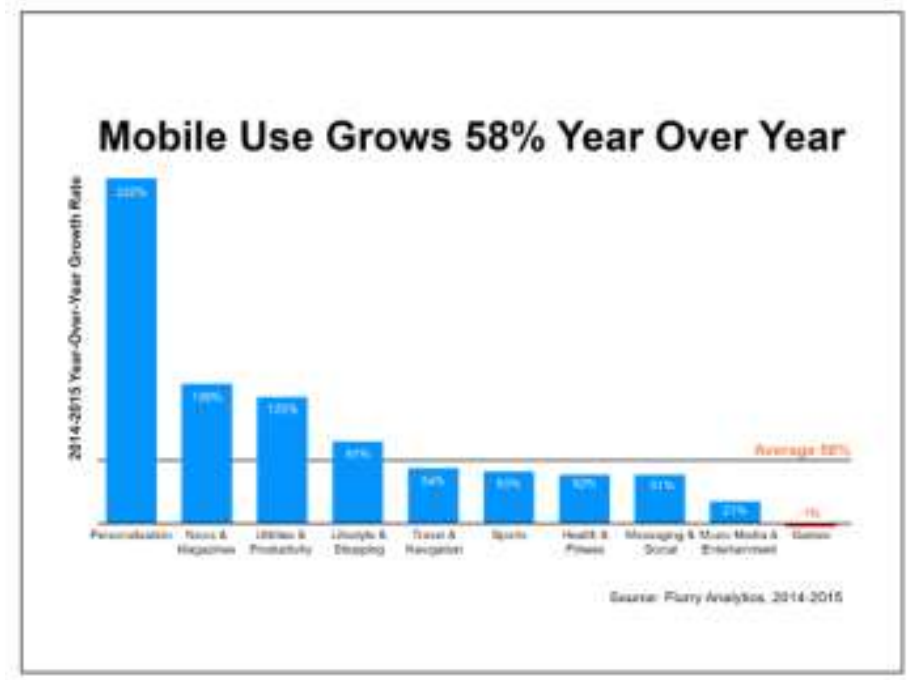

Fig. 1 growth in mobile app usage [8]

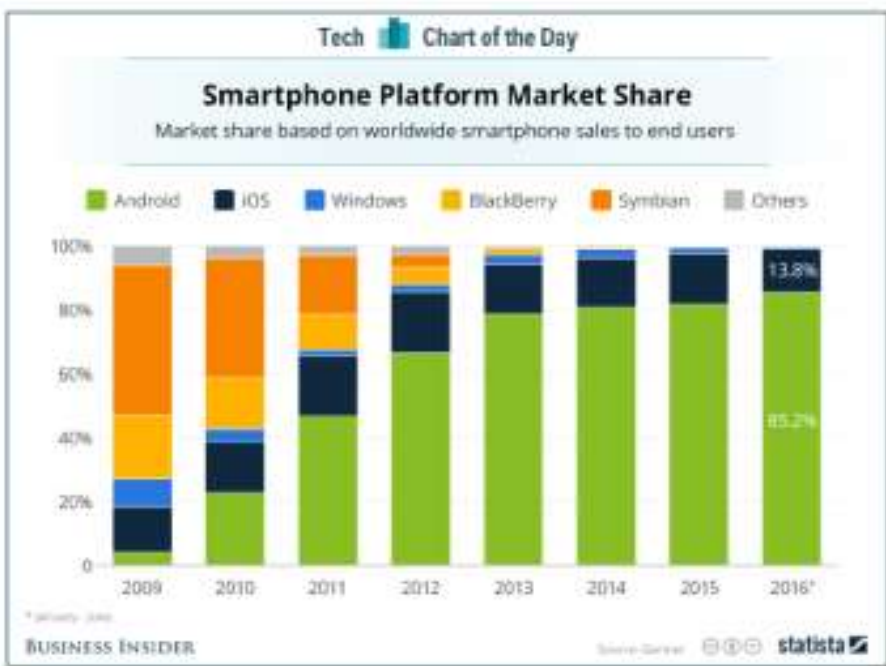

Fig. 2 market share of smartphone platform [9]

This mobile application based on android should be able to provide security on road and ensure justice to the criminals providing information. This application should also provide features so that user can test the speed, match the reading with speed limit chart to admonish the vehicle driver while riding a vehicle and in case of emergency send SMS/MMS/Email to family, friends and law enforcement agencies to share location, journey details, and ask for help.

\section{Related work}


There have been lots of research work on personal safety. Several systems were developed regarding this issue.Discussion on some of these systems are given. Personal safety triggering system [10] is a well-known application. This application is divided into three categories: security threats like personal safety, heart beat based emergency and road accidents. This application mainly focuses on the safety of a person who is driving vehicle. A heart rate monitoring device (Zephyr Bluetooth Heart Rate Device) will be needed to sense the heart beat when he driving the vehicle. If any abnormality is monitored, this application will track the GPS location and location related information will be sent to predefined contact number, email and will be shared on facebook.com wall. User can do the same task by pressing the heart symbol button in app.If user do not interact for 14 second then GPS will track the location and send alert message.

DAAK [11] is a well-known android application in Bangladesh. Anyone can use this application to avoid unpleasant situation. For emergency press the power button and volume button of mobile. Then call for help will reach various places including nearest police station, family and people residing within $1 \mathrm{~km}$ radius. To get out of any uncomfortable situation anyone can use fake call option and can find all important govt. numbers. Be Safe- the Women Safety App [12] especially works for women to prevent sexual crimes, robbery etc. This app allows user to save four contact for emergency. In an emergency the SOS button will be pressed and a message will be sent to those four contact with current location for help. Several thesis in [13, 14, and 15] has been done on this topic. Analyzing these works some limitations has been found. To ensure personal safety, some of these proposed systems needs extra device which will cost money.Again these researches mainly focused on the safety of women but safety men as well as women during journey has not been discussed in any of these theses. Again the phone itself can be robbed or lost; no system has ensured safety of the phone along with personal safety. If robbery/hijacking occurs during riding vehicle due to the irresponsibility of the driver, there is no way to find out the vehicle as well as driver later and provide information to the law enforcement agencies.

\section{Proposed system}

To provide complete security during journey on road, an android based application named 'Journey Safety' has been proposed. This proposed application is concerned with the protection of life and property. It will provide features to test the speed of vehicle, match the reading with speed limit chart, capture photo of the driver and vehicle's registration number plate, instant geographical location, send SMS/MMS/Email to family, friends and law enforcement agencies in case of emergency and ask for help. This application will contain another smart solution for safety purpose. If user is afraid to fall in danger, then a timer can be set. If user is unable to press that button within that time period, then the application will assume that user is in danger and it would notify user's family, friends and law enforcement agencies. Fig. 3 shows the block diagram of the proposed application.

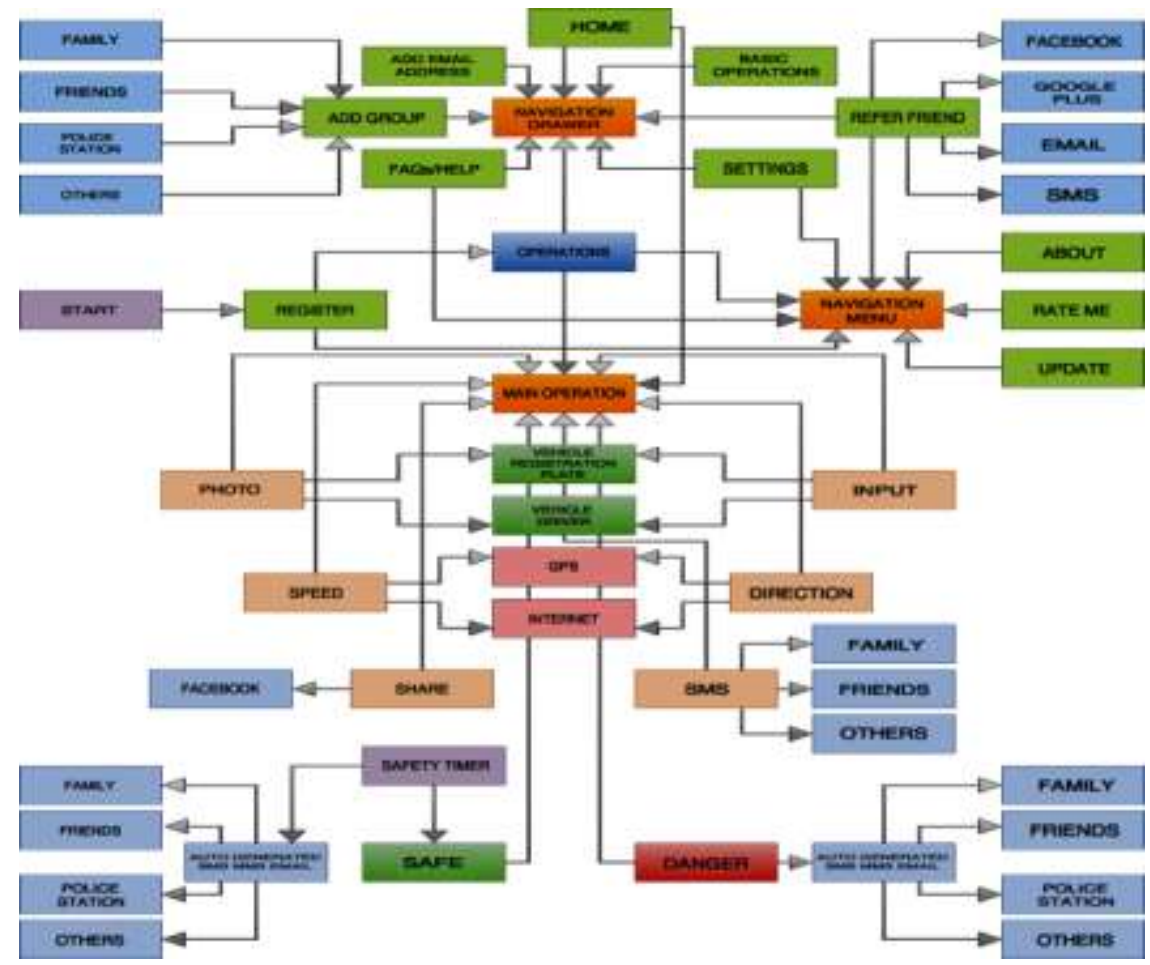

Fig. 3 block diagram of the proposed application 


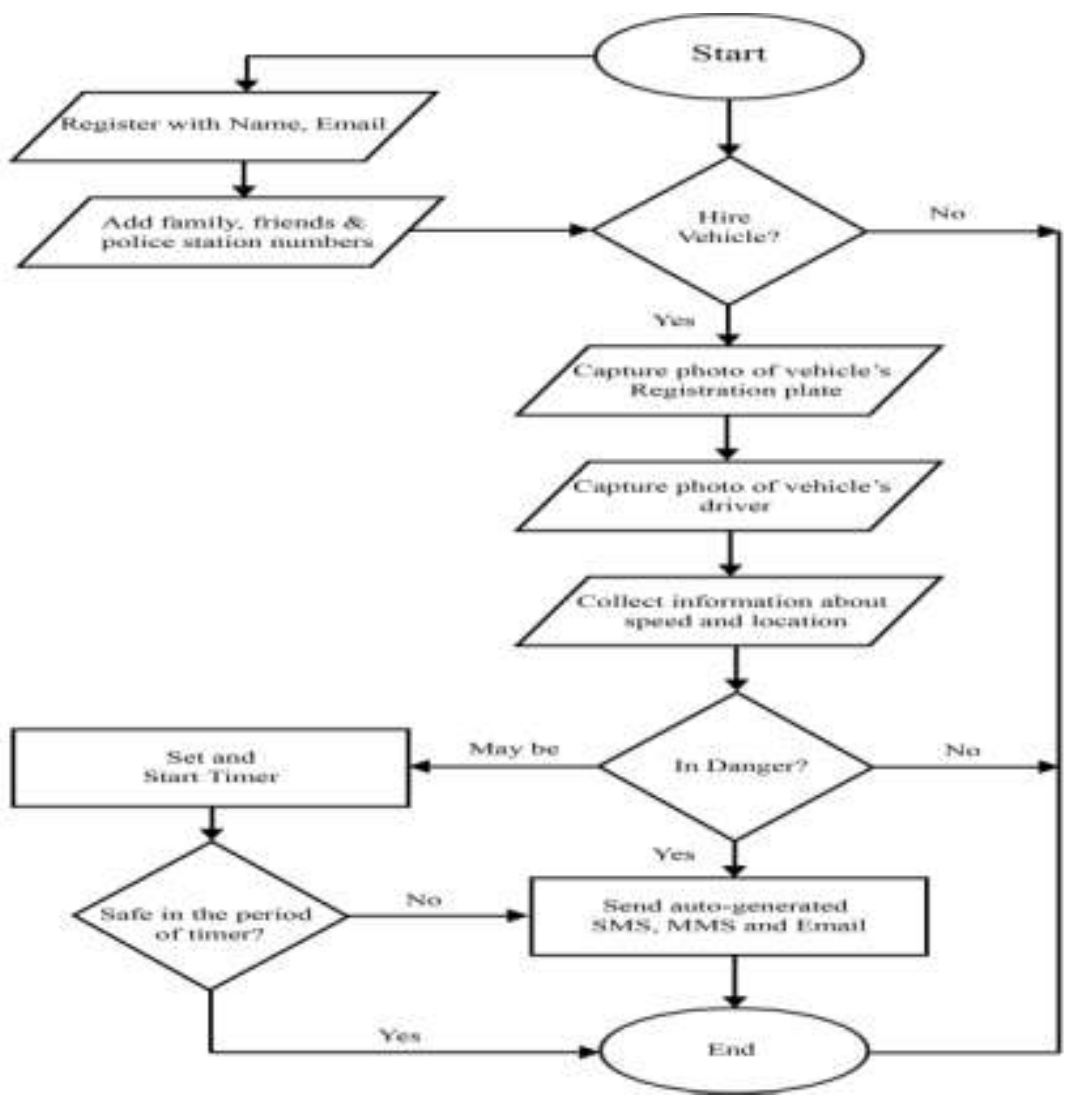

Fig. 4 Flow chart of the proposed application

Fig. 4 shows the flow chart of the proposed solution. In this proposed system, digital camera of the mobile phone will be used to capture photo of the vehicle's number plate as well as driver. Embedded GPS Tracking system of mobile phone will be used to identify the geographical location of the user. Google Map will be used to mark the location of the user and store it to keep track of the journey route. A speed tester will be embedded with the application to test the speed of the vehicle. Although there have been lots of work on personal safety but security during journey is not ensured by any of those. Personal security as well as security of the phone during journey will be ensured by this proposed application. If robbery/hijacking occurs because of the involvement of the driver of vehicle, this application will help to find out the vehicle as well as driver later.

\section{Implementation}

When the application is started, the welcome screen will appear first (Fig. 5). After the appearance of welcome screen, the registration screen will appear (Fig. 6). User has to register for this application with name, Email address, phone number, gender and auto loaded IMEI number. After registration main operation screen will appear (Fig. 7). There are three options to work in the main operation screen - navigation drawer, navigation menu and main operation.

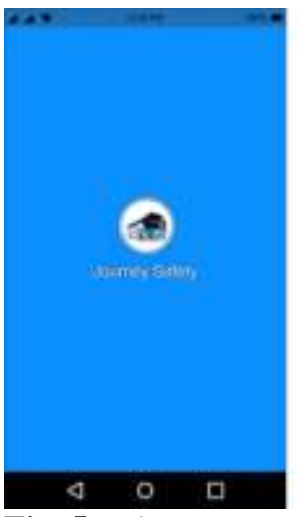

Fig. 5 welcome screen

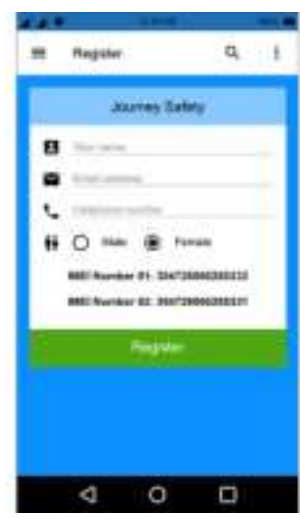

Fig. 6 register screen

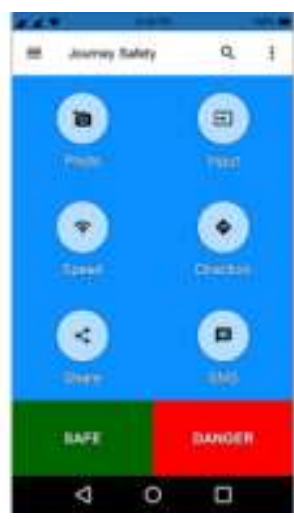

Fig. 7 operation screen

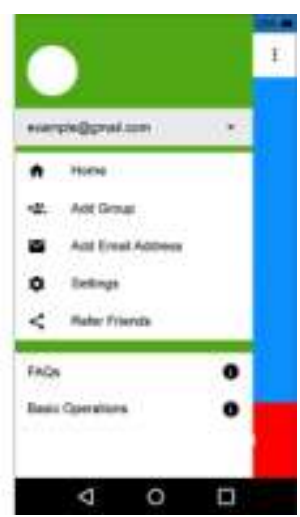

Fig. 8 app navigation 
In the navigation drawer, there are seven options- Home, Add Group, Add Email Address, Settings, Refer Friends, FAQs and Basic Operations (Fig. 8). Whenever 'Home' button is pressed, main operation screen will appear. 'Add Group' option will allow user to add four groups- family (Fig. 17), friends, police station (Fig. 16) and others. Member in each group can be added manually providing name and cell phone number or directly from phone book (Fig. 15). 'Add Email Address' option will allow user to enter name and Email address to send journey related information during danger.Using 'Settings' option user can set share settings, safety timer and alarm (Fig. 18). To share journey related information on facebook, user has to set user id and password in 'Share Settings' option (Fig. 18). During Journey if user feels insecurity or threat to his/her life and won't get any chance to press the danger button at proper time, then user can set safety timer and alert type and tone. Later if user is unable to press the 'Safe' button within that defined safety time an auto-generated SMS, MMS and Email will be sent to previously defined group of family, friends and police station. With 'Refer Friend' option user can share journey safety app with his friends via facebook, Email, SMS, Google Plus, Whatsapp etc.

In the navigation menu, there are seven options- Register, About, Help, Settings, Refer Friends, Rate me and Update. From the 'Register' option, user can update registration related information. Basic information about the application is in the 'About' option. Function of 'Settings' and 'Refer Friends' options is similar to the navigation drawer's 'Settings' and 'Refer Friends' options. Using 'Rate me' and 'Update' option user can consecutively rate the application and get latest update of the application from Google play store.

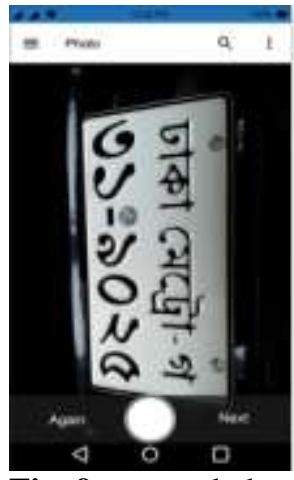

Fig. 9 captured photo

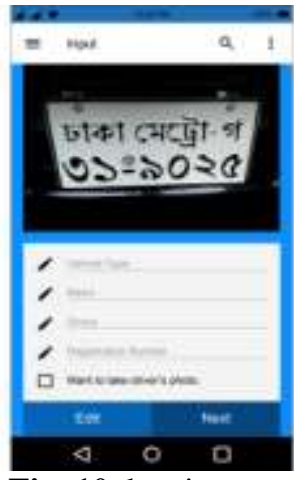

Fig. 10 data input

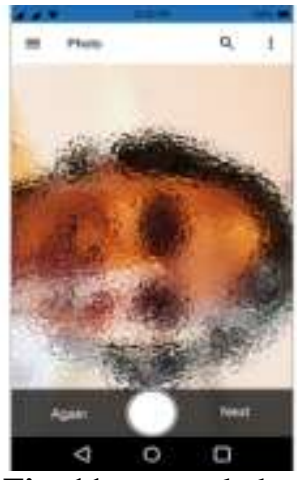

Fig. 11 captured photo

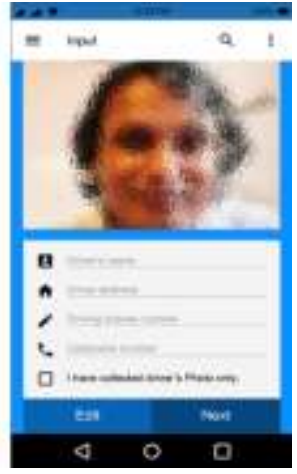

Fig. 12 data input

In main operation, there are eight options- Photo, Input, Speed, Direction, Share, SMS, Safe/Green button and Danger/Red button (Fig. 7). By choosing 'Photo' option, user can capture photo of the vehicle's registration number plate (Fig. 9). After capturing photo, pressing 'Next' button 'Input' option will open. Photo of the registration plate number will appear on top of this window to make it easy for the user to enter vehicle type, metro, group and registration number accurately (Fig. 10). By checking the checkbox appearing at the bottom of the screen (Fig. 10), user can capture photo of vehicle's driver as shown in (Fig. 11). Pressing 'Next' button will again open 'Input' option. If it was possible to collect driver's name, address, driving license number and mobile number, then these information will be inserted in (Fig. 12). Otherwise user will check in the checkbox shown below and press 'Next' will appear to test vehicle speed. 'Speed' option will allow user to test the speed using GPS based speedometer and to enable this option, GPS and internet are mandatory (Fig. 13). If needed speedometer can be reset. Additionally, user can admonish vehicle driver watching the road wise speed limit chart. Last reading of speedometer will remain saved in the application database. 'Direction' option is mainly based on Google Map. This option will allow user to find direction to the destination and collect instant geographical location (Fig. 14). Share option will allow user to share journey information on facebook wall. SMS option will allow user to send journey information to the previously stored group.

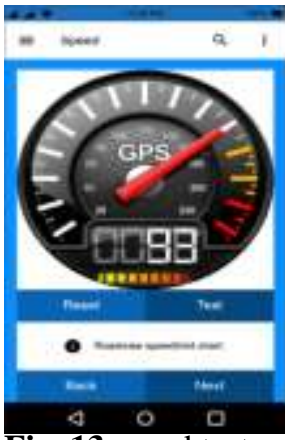

Fig. 13 speed test

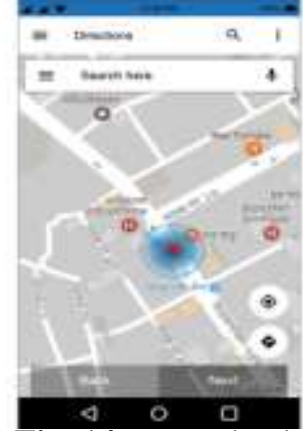

Fig. 14 gps navigation

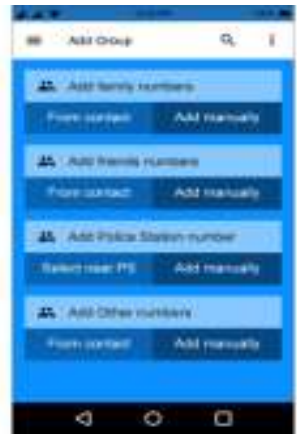

Fig. 15 add group

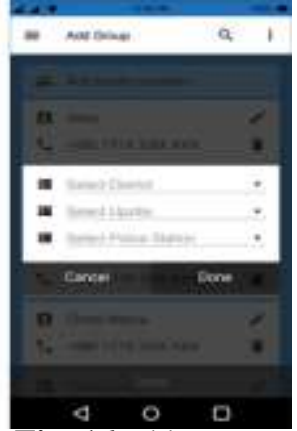

Fig. 16 add group 


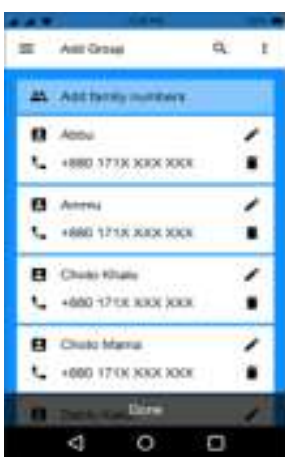

Fig. 17 add group

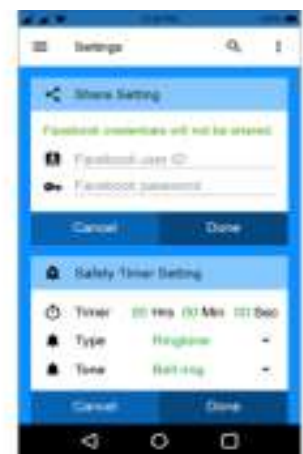

Fig. 18 share/timer settings

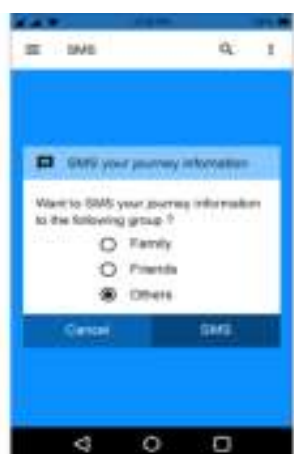

Fig.19 sms sending

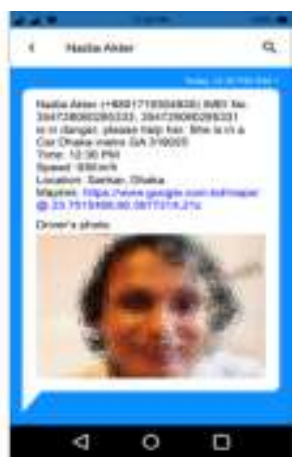

Fig. $20 \mathrm{mms}$ format

'Safe' option provides smart solution. During Journey if user is afraid of any insecurity or threat to his/her life and won't get any chance to press the danger button at proper time, then user can set safety timer, alert type and tone (Fig. 18). Later if user is unable to press the 'Safe' button within that defined safety time an auto-generated SMS, MMS and Email will be sent to previously defined group of family, friends and police station. 'Danger' option will allow user to send auto-generated SMS, MMS and Email will be sent to previously defined group of family, friends and police station.

\section{Discussion}

At present android smartphones with different configuration and versions of different companies are available throughout the global market. To meet various types of demand smartphones with different screen sizes and android versions are circulating the market. This is why developing application considering all these things is a challenge for the application developer. Again proposed system demands everlasting high speed internet and GPS navigation in the smartphone which may cause high battery consumption. Although power banks can be a solution to this problem. People use limited internet package to reduce cost which may restrain everlasting high speed internet. But as life is more valuable than the cost of internet, so these requirements for security purpose should be fulfilled.

\section{Conclusion}

Journey Safety application will alert drivers of vehicle as well as increase public awareness capturing photo of vehicle's driver and registration number plate. It is known to everyone that prevention is better than cure. This application can provide impressive user experience of integrated form of smart phone and its ultramodern hardware.Operations of this application is very user friendly. In the conclusion it can be said that security in every day's journey can be ensured by Journey Safety Application.

\section{Future work}

In a populated country like Bangladesh it is possible to provide individual's safety on journey as well as financial security of vehicle organizations by Journey Safety Application. Efficiency of this application can be increased by adding some extra features to this application as well as connecting it with a dedicated server. Along with general user, owner of vehicles also will be able to track the vehicle as well as calculate how many kilometers the vehicle has been driven. Storing Information about drivers, later it can be checked that whether or not the driver is real. Above all in future this application with some extra added features can be beneficial to the Bangladesh Road Transport Authority (BRTA) to ensure highest service to the general people. In a riverine country like Bangladesh, a new angle to the usage of this application can be added by putting GPS tracker in water transports. Thus it will be possible to track lost, sunk water transports. By updating 'Journey Safety' application for smart wear, smart TV, smart auto, its usability can be enhanced. It is believed by the authors of this thesis that the day is not too far away when a specialized application like Journey Safety will be able to ensure complete safety on journey. 


\section{References}

[1]. Peden M, Scurfield R, Sleet D, Mohan D, Jyder A, Jarawan E, Mathers C (Eds) (2004). World Report on Road Traffic Injury Prevention. Geneva: World Health Organization.

[2]. Peden M, Hyder AA, Road traffic injuries are a global public health problem, BMJ, 2002, 1153-54.

[3]. Arif A. Lowest motor vehicle but highest road accidents in Bangladesh, Amar Desh, Jan 14, 2012, page 1, column 6.

[4]. The Daily Star, Road crashes killed at least 8,642 last year, Report, January 10, 2016. (http://www.thedailystar.net/frontpage/roadcrashes-killed-least-8642-last-year-199699, accessed 24 December, 2016)

[5]. Numbeo, Crime in Bangladesh, (December, 2016), (https://www.numbeo.com/crime/country_result.jsp?country=Bangladesh, accessed December 25, 2016).

[6]. Report of the Secretary-General, State of crime and criminal justice worldwide (A/CONF.222/4), Thirteenth United Nations Congress on Crime Prevention and Criminal Justice, January 19, 2015, 5-7.

[7]. Note by the Secretariat, World crime trends and emerging issues and responses in the field of crime prevention and criminal justice (E/CN.15/2016/1), Economic and Social Council, March 29, 2016, 13-14.

[8]. Flurry Analytics (2014-2015). ( http://flurrymobile.tumblr.com/post/136677391508/ stateofmobile2015, accessed Jan 5, 2016)

[9]. Jeff Dunn. (August 22, 2016), (http://www.businessinsider.com/smartphone-market-share-android-ios-windows-blackberry-2016-8, accessed December, 2016)

[10]. Ashokkumar Ramalingam, and Prabhu Dorairaj, Personal Safety Triggering System on Android Mobile Platform, International Journal of Network Security \& Its Application (IJNSA), 4(4), 2012, 179-197.

[11]. Rupam IT Limited. (2015). Daak (Version 1.3), (https://play.google.com/store/apps/details?id=com.rupamit.daak, accessed 24 December, 2016)

[12]. TechBrotherz Apps Tools, Be Safe- the Women Safety App (Version 1.0), ( https://play.google.com/store/apps/details?id=dr.tech brotherz.womensafety.besafe, accessed 24 December, 2016)

[13]. Dr. Sridhar Mandapati, Sravya Pamidi, and Sriharitha Ambati, A Mobile Based Women Safety Application (I Safe Apps), IOSR Journal of Computer Engineering (IOSR-JCE), 17(1), 2015, 29-34.

[14]. S.Sangeetha, and P.Radhika PG Scholar, Application for Women Safety, IOSR Journal of Computer Engineering (IOSR-JCE), 17(3), 2015, 01-04.

[15]. Divya S, Vinitha M, Logeshwari B, and Indumathi P, A Women Secure Mobile APP for Emergency Usage (GO SAFE APP), International Journal of Research in Engineering and Technology (IJRET), 5(3), 2016, 412-414. 